\title{
Tests and analyses on mechanical characteristics of dwarf-dense-early major cotton variety stalks
}

\author{
Rongqing Liang ${ }^{1,2}{ }^{-}$, Xuegeng Chen ${ }^{1,2}$, Bingcheng Zhang ${ }^{1,2}$, Xiangbin Peng ${ }^{1,2}$, Hewei Meng ${ }^{1,2}$, \\ Peng Jiang ${ }^{1,2}$, Jiali Li ${ }^{1,2}$, Pengfei Zhou ${ }^{1,2}$, and Za Kan ${ }^{1,2} *$ \\ ${ }^{1}$ College of Mechanical and Electrical Engineering, Shihezi University, Shihezi 832000, China \\ ${ }^{2}$ Key Laboratory of Northwest Agricultural equipment, Ministry of Agriculture and Rural Affairs, Shihezi 832000, China \\ Received December 30, 2019; accepted May 18, 2020
}

\begin{abstract}
The influence of the variation in water content, sampling location and loading speed on the shearing and across-compression mechanical characteristics of dwarf-denseearly major cotton variety stalks was analysed. The second-order response models of the factors $v s$. the maximum shear force and critical across-compression failure force were built using the response surface methodology. Besides, the sampling location and water content have a significant influence over the maximum shear force and critical across-compression failure force, especially the sampling location. Both the maximum shear force and critical across-compression failure force reach a theoretical maximum when the water content is $10 \%$, the sampling location is the lower part and the loading speed is $40 \mathrm{~mm} \mathrm{~min}^{-1}$. When the sampling location is the lower part, optimization is carried out assuming the theoretical minimum of the maximum shear force and critical across-compression failure force as the optimization target. In this case, the loading speed is $20 \mathrm{~mm} \mathrm{~min}^{-1}$, while the water content is between 30 and $50 \%$. This indicates that the parameter range requires a low power consumption during the crushing of film residue mixtures. The test data can provide some theoretical references for the technical research and equipment development for the crushing of film.
\end{abstract}

Keywords: cotton stalk, dwarf-dense-early, multiple factors, mechanical characteristics

\section{INTRODUCTION}

Cotton is an important global economic crop, and its fibres and seeds have a unique economic value (Wanjura et al., 2014). China is one of the world's major cotton producing countries, and the cotton plantation area of China is mainly distributed in the Yangtze River Basin, the Yellow River Basin, and Northwest China (Zhang et al., 2019). Xinjiang is located in Northwest China, where the climate

\footnotetext{
*Corresponding author e-mail:kz-shz@163.com

is dry and with little precipitation. The film mulching planting method (Liu et al., 2008; Dong et al., 2013) is used for all cotton in Xinjiang. In the last 30 years, with the popularization and application (Chen et al., 2010) of a complete set of new high-efficiency cotton planting technologies such as broad film mulching, mulched drip irrigation, precision seeding, etc., Xinjiang has become the most typical cotton producing area in Northwest China. The total cotton plantation area and total cotton yield of Xinjiang in 2018 were $2492 \times 10^{3} \mathrm{hm}^{2}$ and $5111 \mathrm{kt}$, respectively, accounting for about 74.3 and $83.8 \%$ of China's total cotton plantation area and total cotton yield respectively. With the expansion of the cotton plantation area and long-term continuous film mulching, film residue pollution to farmland is becoming more and more serious, and film residues after harvesting with machinery wrap a large quantity of cotton stalks, which is extremely unfavourable for the processing of cotton. As shown in Fig. 1, film residue mixtures after harvesting with machinery in cotton fields include residual plastic films, stalks and soil. Cotton stalks are one of the main constituents of film residue mixtures. The mechanical properties of cotton stalks are of much significance with reference to the selection of the appropriate crushing method, crushing machine design, crushing mechanism research, and crushing device development for the separation of film residue mixtures after harvesting with machinery in cotton fields.

In recent years, domestic and foreign scholars have carried out research into the mechanical properties of cotton stalks: Wu et al. (2004) studied the influence of the water content, internode distance, diameter, etc. of cotton stalks 


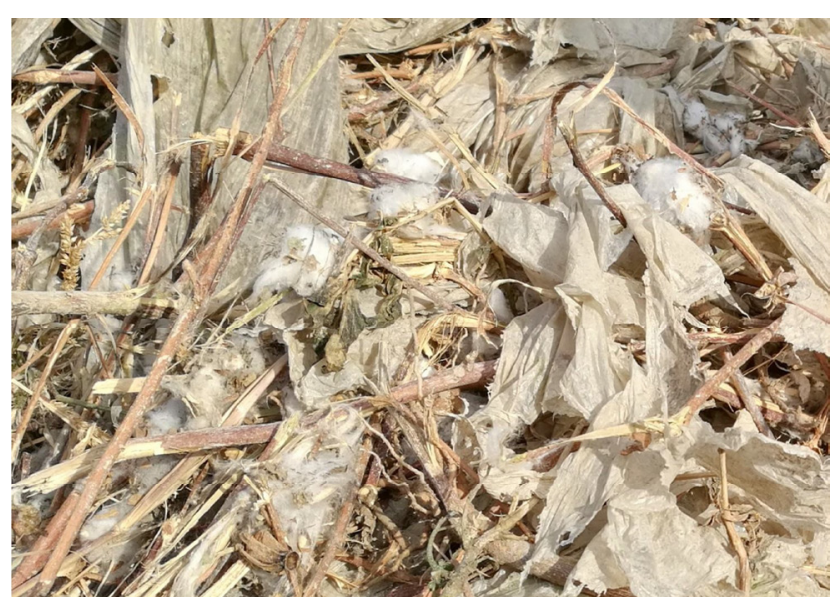

Fig. 1. Film residue mixtures in farmland after harvesting with machinery in Xinjiang.

on the axial compressive modulus of elasticity and on the compressive strength through axial compression tests on the cotton stalks. Jha et al. (2008) built models of the relationship between water content and pressure $v s$. compression characteristics by studying the compression characteristics of shredded cotton stalks, and analysed the variation characteristics of the volume weight, elasticity, and hardness of the shredded cotton stalks during compression. Shen et al. (2010a) performed tensile, compression, and shear tests on the bottom parts of cotton stalks during the harvesting period, and obtained the characteristic parameters of this part of the cotton stalks including maximum failure stress, elastic modulus, etc. Shen et al. (2010b) obtained the stress/strain law and strength limit of cotton stalks through tests on the compression and shearing mechanical properties of cotton stalks. Li (2011) and Du et al. (2011) carried out shearing, compression and bending tests on cotton stalks in different periods, analysed the influence of water content and the different sampling locations of the cotton stalks on the test results, and estimated the power consumption required by each test process. Tan (2013) and Zhang et al. (2014) carried out shearing, bending, tensile and compression tests on cotton stalks respectively, and analysed the variation in the relationship between the mechanical properties of cotton stalks $v s$. their diameter and water content. Liu et al. (2014) measured the tensile strength and elastic modulus of cotton stalks, and analysed the influence of the relationship between the tensile strength and elastic modulus of the cotton stalks vs. the different locations and water contents. Chen et al. (2015) carried out bending and tensile tests on the bottom parts of cotton stalks in different periods. The test results showed that the bending strength and tensile strength of the cotton stalks had negative and positive correlations with water content respectively, the tensile failure load of the samples was 10.9 to 29.8 times their bending failure load, and the difference between the two loads increased with the increase in water content. Ding et al. (2016) conducted shearing tests on cotton stalks in the harvesting period, and obtained the shear force range of cotton stalks from different sampling locations. Gao et al. (2016) analysed the relationship between the water content, sampling location and loading speed of the cotton stalks during the harvesting period $v s$. shear force using the response surface methodology through single-factor tests and central composite tests. Shi et al. (2017) measured the axial and tangential peeling shear strengths of cotton stalks through central composite tests, single-factor tests and comparative tests, and determined the relationship between the sampling location, loading speed and water content $v s$. the peeling shear strengths in all directions. Qin et al. (2017) analysed the relationship between the shearing characteristics of cotton stalks vs. the sampling location, water content and loading speed as well as the relationship between the bending characteristics $v s$. the sampling location and water content, and built relationship models between the various influential factors $v s$. the shearing and bending mechanical characteristics through quadratic regression orthogonal rotation combination tests. Aydın and Arslan (2018) carried out shearing tests on cotton stalks of $0 \sim 150$ and $160 \sim 300 \mathrm{~mm}$ from top to bottom during the growth period, and compared and analysed the characteristic parameters of the two parts of stalks, including the maximum shear force, shear strength, power consumption, etc.

In summary, domestic and foreign scholars have studied the mechanical characteristics of cotton stalks in different regions and in different periods, but there are still too few studies concerning the mechanical characteristics of the stalks of a major cotton variety grown using dwarf-denseearly techniques in Xinjiang. According to the literature (Wu et al., 2004; Tan et al., 2013; Zhang et al., 2014; Ding et al., 2016), mechanical characteristic tests were conducted on these stalks, but only the influences of single factors such as water content, sampling location and loading on the mechanical characteristics of cotton stalks were analysed. In one study (Qin et al., 2017), the relationship models of the factors $v s$. the shearing and bending characteristics of cotton stalks were constructed using the quadratic regression orthogonal method, but the research objects were the stalks of the mid-mature cotton varieties in the cotton planting area in the Southern Tianshan Mountains, Xinjiang; moreover, the mechanical characteristics of compression of the cotton stalks were not studied.

There are some differences in the form, structural characteristics and mechanical characteristics of cotton stalks in different regions, these differences are determined by multiple factors such as the growth environment, cotton varieties, planting patterns, management methods, etc. (Li et al., 2011; Aydin and Arslan, 2018). For this reason, in this paper, shearing and across-compression tests were conducted on cotton stalks using the dwarf-dense-early major cotton variety stalks for the purposes of returning them to the field in the cotton planting area in the Northern Tianshan 
Mountains, Xinjiang as the research objects. The influences of water content, sampling location, loading speed, etc. of the cotton stalks on their shearing and across-compression mechanical characteristics were determined using the response surface methodology. The second-order response models were constructed using single factor terms such as water content, sampling location, and loading speed and their interaction terms $v s$. shearing and across-compression mechanical characteristics of cotton stalks. The ways in which single factor terms and their interaction terms influence the shearing and across-compression mechanical characteristics of cotton stalks was studied and analysed, for the purpose of providing some theoretical references for the technical research and equipment development for the harvesting and processing of cotton stalks and the crushing of film residue mixtures.

\section{MATERIALS AND METHODS}

The cotton stalks for the tests were sampled from the test base of Shihezi University. The cotton variety used was Xinluzao series No. 45, and the cotton planting pattern is a mainstream one-film and six-row planting pattern with staggered broad and narrow rows that is suitable for mechanized cotton harvesting in Xinjiang at present. Technologies such as broad film mulching (mulching film width: $2050 \mathrm{~mm}$ ) and mulched drip irrigation are commonly used in cotton planting, the broad row spacing is $660 \mathrm{~mm}$, the narrow row spacing is $100 \mathrm{~mm}$, and the plant spacing is $130 \mathrm{~mm}$, as shown in Fig. 2. Field sampling was performed on October 15,2019 . The weather was cloudy, and the outdoor temperature was $6 \sim 21^{\circ} \mathrm{C}$. During sampling, the cotton plants were characterized by an upright appearance, there were minor variations in stalk diameter in the same sampling location, few branches, no pests, no damage or cracking, etc. the plants were sampled randomly. After the whole cotton stalk was cut along the ground surface with trimming pliers, the cotton stalk incision was wound with plastic wrap to prevent water loss, then the whole cotton stalk was transported to the laboratory.

In order to derive the influence of the relationship between the shearing and across-compression mechanical characteristics of cotton stalks $v s$. single factor terms such as water content, sampling location, loading speed and their interaction terms, the most important instruments and equipment required during the tests are as follows: DF-9000 universal testing machine (manufacturer: Taiwan High-Speed Rail Testing Instrument Co., Ltd. in China, maximum load: $1000 \mathrm{~N}$, load accuracy: $\pm 0.25 \%$, displacement resolution: $0.001 \mathrm{~mm}$ ), Sartorius MA100 electronic moisture tester (manufacturer: Sartorius Stedim Biotech $\mathrm{GmbH}$ in Germany, mass accuracy: $0.001 \mathrm{~g}$, water content accuracy: $0.01 \%$ ), electrothermal blowing dry box, JMB5003 electronic balance (manufacturer: Zhejiang a

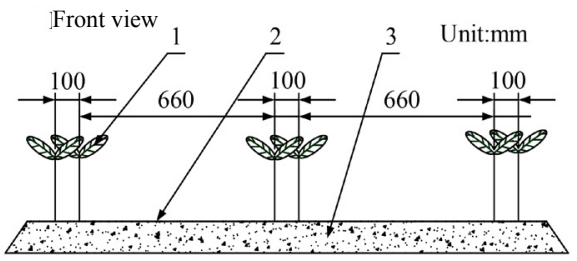

b

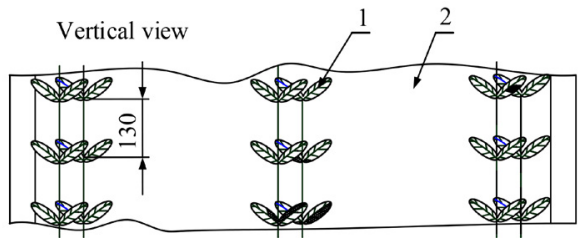

Fig. 2. Planting pattern of a major cotton variety grown using dwarf-dense-early techniques in Xinjiang.

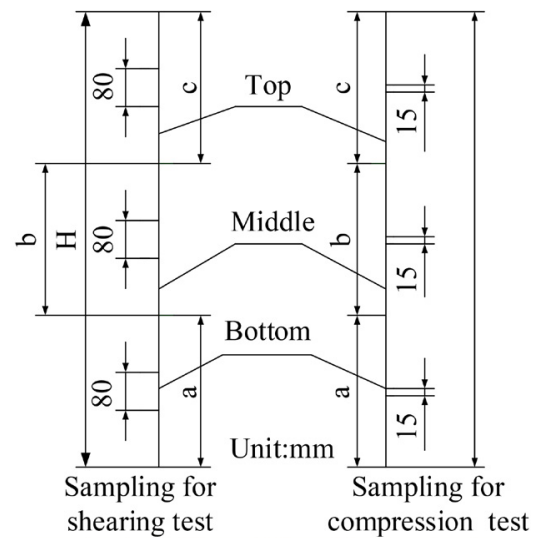

Fig. 3. Sampling method of cotton stalks for shearing and acrosscompression tests.

Jiming Weighing and Calibration Equipment Co., Ltd. in China, measuring accuracy: $0.001 \mathrm{~g}$ ), vernier calipers, trimming pliers, shearing and compression test aids, etc.

After the randomly collected cotton stalks were transported to the laboratory, the side branches and leaf buds were first removed using trimming pliers. At the same time, the water content at the bottom incision of the cotton stalk was measured and found to be $67.9 \pm 1.5 \%$ using a Sartorius MA100 electronic moisture tester. It should be noted that when the film residue mixtures were crushed, the cotton stalks were subjected to shearing and lateral extrusion forces to a large extent. Therefore, only the shearing and across-compression mechanical characteristics of the cotton stalks were studied during tests on the mechanical characteristics of cotton stalks in this paper. Each cotton stalk was divided into upper, middle and lower parts according to plant height. Samples with a total length of $80 \pm 0.5$ or $15 \pm 0.5 \mathrm{~mm}$ were cut from the centre of each part (Fig. 3), for use in shear tests and across-compression tests respectively. An effort was made to avoid stalk nodes during sample cutting. Three samples were prepared for each group of tests according to the test requirements. The basic parameters of the cut samples are shown in Table 1 . 
In addition, due to the small diameter of the cotton stalks, the samples could not be prepared (Meng et al., 2005) normatively in accordance with the requirements of timber and lumber standards GB/T 1935-2009 and GB/T 1937-2009; therefore, referring to literature (Li et al., 2011; Du et al. 2011), etc., cotton stalk samples with equal diameters were prepared for use in shearing and across-compression tests.

The water content of the cotton stalks was modulated according to GB/T 1928-2009, GB/T 1931-2009 and the following study (Hirai et al., 2002). After placing the samples into an electrothermal blowing dry box for drying at $103 \pm 2^{\circ} \mathrm{C}$ for $8 \mathrm{~h}, 2 \sim 3$ samples were selected and weighed with a JMB5003 electronic balance; after $2 \mathrm{~h}$, they were weighed again. The two weighed mass results of the samples were compared; if their relative change was no more than $0.5 \%$, they were considered to be absolutely dry. After the thorough soaking of the absolutely dry samples with clean water, the test water content was modulated using an electrothermal blowing dry box at $45 \pm 2{ }^{\circ} \mathrm{C}$ according to the set water content gradient. After completing the modulation of the water content, the DF-9000 universal testing machine was used to carry out shearing and across-compression tests on the cotton stalks, which are referred to in the timber and lumber standards GB/T 1935-2009 and GB/T 1937-2009 as well as the test steps. Before the test began, the working stroke of the universal testing machine was adjusted. After that, the sample was placed in the shear and compression mould of the testing machine. Then, a load was added to the sample according to the preset loading speed. Finally, the test result data on the computer display interface were noted. The tests for each group were repeated 3 times, and the average values were taken.

In order to investigate the influences of water content $A$, sampling location $B$ and loading speed $C$ on the mechanical characteristics of cotton stalks, response surface methodology was used in the study of shearing and across-compression mechanical characteristics of cotton stalks assuming the maximum shear force $\left(F_{\max }\right)$ and critical across-compression failure force $\left(F_{c}\right)$ of the cotton stalks as the test response indexes and different water contents $A$, different sampling locations $B$, and different loading speeds $C$ as the test influence factors in this study. According to the modulation method mentioned above, the water content of the cotton stalks was adjusted to 10,30 and $50 \%$. The sampling location was divided into upper, middle, and lower parts, and the loading speed gradient was set at 20, 30 and $40 \mathrm{~mm} \mathrm{~min}^{-1}$. The test influence factors and set level codes are shown in Table 2.

According to the mechanical characteristic test response indicators, the influencing factors and the position of the sampled part of the cotton stalks described above, the BoxBehnken module in the data processing software Design expert was used to design the response surface test. The significance of the influences of single-factor terms such as different water contents $A$, different sampling locations $B$,
Table 1. Basic parameters of cotton stalks for shearing and compression tests

\begin{tabular}{llcc}
\hline Test name & $\begin{array}{l}\text { Sampling } \\
\text { location }\end{array}$ & $\begin{array}{c}\text { Length } \\
(\mathrm{mm})\end{array}$ & $\begin{array}{c}\text { Average stalk } \\
\text { diameter }(\mathrm{mm})\end{array}$ \\
\hline \multirow{2}{*}{ Shearing test } & upper & & 6.33 \\
& middle & $80 \pm 0.5$ & 6.78 \\
& lower & & 9.24 \\
Across- & upper & & 6.79 \\
compression & middle & $15 \pm 0.5$ & 7.33 \\
test & lower & & 9.6 \\
\hline
\end{tabular}

Table 2. Test factors and level codes

\begin{tabular}{|c|c|c|c|}
\hline Level & $\begin{array}{c}\text { Water } \\
\text { content } \\
(\%) \\
A\end{array}$ & $\begin{array}{c}\text { Sampling } \\
\text { location } \\
B\end{array}$ & $\begin{array}{c}\text { Loading speed } \\
\left(\mathrm{mm} \mathrm{min}^{-1}\right) \\
C\end{array}$ \\
\hline-1 & 10 & upper & 20 \\
\hline 0 & 30 & middle & 30 \\
\hline 1 & 50 & lower & 40 \\
\hline
\end{tabular}

Table 3. Response surface test and result

\begin{tabular}{ccccrr}
\hline Test No. & $A$ & $B$ & $C$ & \multicolumn{1}{c}{$y_{1}$} & \multicolumn{1}{c}{$y_{2}$} \\
\hline 1 & -1 & -1 & 0 & 125.83 & 143.32 \\
2 & 1 & -1 & 0 & 77.16 & 80.63 \\
3 & -1 & 1 & 0 & 392.43 & 361.70 \\
4 & 1 & 1 & 0 & 359.16 & 243.25 \\
5 & -1 & 0 & -1 & 68.73 & 190.29 \\
6 & 1 & 0 & -1 & 96.88 & 91.21 \\
7 & -1 & 0 & 1 & 176.51 & 182.29 \\
8 & 1 & 0 & 1 & 103.05 & 92.12 \\
9 & 0 & -1 & -1 & 79.14 & 97.91 \\
10 & 0 & 1 & -1 & 347.49 & 215.39 \\
11 & 0 & -1 & 1 & 67.11 & 83.25 \\
12 & 0 & 1 & 1 & 346.1 & 363.90 \\
13 & 0 & 0 & 0 & 98.88 & 146.13 \\
14 & 0 & 0 & 0 & 106.86 & 120.41 \\
15 & 0 & 0 & 0 & 98.77 & 167.77 \\
16 & 0 & 0 & 0 & 102.43 & 141.40 \\
17 & 0 & 0 & 0 & 98.71 & 136.50 \\
\hline
\end{tabular}

different loading speeds $C$ and their interaction terms were studied and analysed by analysing the test results and building the corresponding second-order response models. The response surface test scheme is shown in Table 3. The $F_{\max }$ and $F_{c}$ of the cotton stalk were tested in 17 groups, and the tests for each group were repeated three times, making a total of 102 tests. After the tests were finished, $\bar{F}_{\max }$ and $\bar{F}_{c}$ 
of the cotton stalks were obtained by calculating the average of the 3 repeated tests. For convenience of expression, the $\bar{F}_{\max }$ and $\bar{F}_{c}$ are characterized by $y_{1}$ and $y_{2}$, respectively.

\section{RESULTS AND DISCUSSION}

Under different loading conditions, a shearing test and an across-compression test were conducted respectively on the cotton stalk samples with different water contents and different sampling locations. The results obtained from the two tests are shown in Table 3. Based on this, a regression variance analysis was performed on the test results in Table 3 using the Analysis of Variance (ANOVA) module in the Design expert data processing software; in addition, second-order response models were built using different water contents $A$, different sampling locations $B$ and different loading speeds $C v s . F_{\max }$ and $F_{c}$ of the cotton stalks, in addition, the degree of influence of the single factor terms and their interaction terms on the mechanical characteristics of the cotton stalks was analysed. Table 4 displays the results obtained from the regression variance analysis of the test results for $F_{\max }$ and $F_{c}$ of the cotton stalks in Table 3.

According to the regression variance analysis of $F_{\max }$ of the cotton stalks shown in Table 4 , the single factor term $B\left(\mathrm{p}<1 \times 10^{-4}\right)$ and the interaction term $B^{2}\left(\mathrm{p}<1 \times 10^{-4}\right)$ are extremely significant factors affecting $F_{\max }$ of the cotton stalks, while the single factor term $A(0.01<\mathrm{p}=0.04 \leq 0.05)$ and the interaction term $A C(0.01<\mathrm{p}=0.03 \leq 0.05)$ are significant factors affecting $F_{\max }$ of cotton stalks; the $\mathrm{p}$ value of the other factor terms is $>0.05$, so they are non- significant influencing factors for $F_{\max }$ of the cotton stalks. The order of the extremely significant influencing factors and significant influencing factors affecting $F_{\max }$ of the cotton stalks is as follows: $B>B^{2}>A C>A$.

In addition, according to the regression variance analysis, the obtained model coefficient of the test result is $\mathrm{p}<1 \times 10^{-4}$, the determination coefficient $\mathrm{R}^{2}=0.99$, the corrected determination coefficient $\mathrm{R}_{a d j}^{2}=0.98$, the coefficient of variation $C V=11.09 \%$, and the predicted determination coefficient $\mathrm{R}_{\text {Pred }}^{2}=0.84$. This indicates that the influencing factors $A, B$ and $C$ have a high degree of correlation with $F_{\max }$ of the cotton stalks and a second-order response model with a high degree of fitting response may be obtained by taking the influencing factors $A, B$ and $C$ as variables and $F_{\max }$ of the cotton stalks as the response index. This secondorder response model may be used to better predict and optimize $F_{\max }$ of cotton stalks. The second-order response model obtained according to the regression variance analysis result and coding factors is shown in Eq. (1):

$$
\begin{gathered}
\hat{y}_{1}=101.1-15.91 A+137 B+12.57 C+3.85 A B \\
-25.4 A C+2.66 B C+19.42 A^{2}+118.1 B^{2}-9.26 C^{2}
\end{gathered}
$$

In the case of only considering the influences of both extremely significant factors and significant factors on the second-order response model, it can be further simplified as follows:

$$
\hat{y}_{1}=101.1-15.91 A+137 B-25.4 A C+118.1 B^{2} .
$$

\begin{tabular}{|c|c|c|c|c|c|c|c|c|c|}
\hline \multirow{2}{*}{ Source } & \multirow{2}{*}{$\mathrm{df}$} & \multicolumn{4}{|c|}{$y_{1}$} & \multicolumn{4}{|c|}{$y_{2}$} \\
\hline & & $\mathrm{SS}$ & MS & $\mathrm{F}$ value & p-value & SS & MS & F value & $\mathrm{p}$-value \\
\hline Model & 9 & $2.2 \times 10^{5}$ & 24177 & 75.32 & $<1 \times 10^{-4 * *}$ & $1.2 \times 10^{5}$ & 13026 & 24.61 & $2 \times 10^{-4 * *}$ \\
\hline$A$ & 1 & 2024 & 2024 & 6.31 & $0.04 *$ & 17149 & 17148 & 32.4 & $0.001 * *$ \\
\hline$B$ & 1 & $1.5 \times 10^{5}$ & $1.5 \times 10^{5}$ & 467.8 & $<1 \times 10^{-4 * *}$ & 75880 & 75880 & 143.4 & $<1 \times 10^{-4 * *}$ \\
\hline$C$ & 1 & 1263 & 1263 & 3.94 & 0.088 & 2009 & 2008 & 3.79 & 0.092 \\
\hline$A B$ & 1 & 59.29 & 59.29 & 0.18 & 0.68 & 777.3 & 777.3 & 1.47 & 0.265 \\
\hline$A C$ & 1 & 2581 & 2581 & 8.04 & $0.025^{*}$ & 19.85 & 19.85 & 0.037 & 0.852 \\
\hline$B C$ & 1 & 28.3 & 28.3 & 0.088 & 0.775 & 6656 & 6656 & 12.58 & $0.009^{* *}$ \\
\hline$A^{2}$ & 1 & 1589 & 1589 & 4.95 & 0.062 & 196.1 & 196.07 & 0.37 & 0.562 \\
\hline$B^{2}$ & 1 & 58718 & 58718 & 182.9 & $<1 \times 10^{-4 * *}$ & 14144 & 14144 & 26.72 & $0.001 * *$ \\
\hline$C^{2}$ & 1 & 361.1 & 361.1 & 1.13 & 0.324 & 445.7 & 445.7 & 0.84 & 0.389 \\
\hline Residual & 7 & 2247 & 321 & & & 3705 & 529.3 & & \\
\hline Lack of fit & 3 & 2196 & 731.9 & 57.39 & 0.001 & 2528 & 842.6 & 2.86 & 0.168 \\
\hline Pure error & 4 & 51.01 & 12.75 & & & 1177 & 294.2 & & \\
\hline \multirow[t]{2}{*}{ Cor total } & 16 & $2.2 \times 10^{5}$ & & & & $1.2 \times 10^{5}$ & & & \\
\hline & & \multicolumn{4}{|c|}{$\begin{array}{c}\mathrm{R}^{2}=0.99, \mathrm{R}_{a d j}^{2}=0.98, \\
C V=11.09 \%, \text { Pred R-Squared }=0.84\end{array}$} & \multicolumn{4}{|c|}{$\begin{array}{c}\mathrm{R}^{2}=0.97, \mathrm{R}_{a d j}^{2}=0.93, \\
C V=13.69 \% \text {, Pred R-Squared }=0.65\end{array}$} \\
\hline
\end{tabular}

Table 4. Regression variance analysis of the mechanical characteristic test results of cotton stalks

*Significant factor $(0.01<\mathrm{p} \leq 0.05), * *$ extremely significant factor $(\mathrm{p} \leq 0.01), \mathrm{p}>0.05$ non-significant factor. SS is sum of squares, MS is mean squares. 
According to the regression variance analysis of the across-compression test result of cotton stalks shown in Table 4 , the single factor terms $A(\mathrm{p}=0.001 \leq 0.01)$ and $B\left(\mathrm{p}<1 \times 10^{-4}\right)$ and the interaction terms $B^{2}(\mathrm{p}=0.001 \leq 0.01)$ and $B C(\mathrm{p}=0.009 \leq 0.01)$ are extremely significant factors affecting $F_{c}$ of the cotton stalks. There is no significant influencing factor in this regression variance. The $p$ value of other single factor terms and interaction terms is $>0.05$, so they are non-significant factors for $F_{c}$ of cotton stalks. Therefore, according to the value of $\mathrm{p}$, the order of the extremely significant influencing factors affecting $F_{c}$ of cotton stalks is as follows: $B>A>B^{2}>B C$.

In addition, according to the regression variance analysis, the obtained model coefficient of the test result is $\mathrm{p}=2 \times 10^{-4}$ which is far smaller than 0.01 , the determination coefficient $\mathrm{R}^{2}=0.97$, the corrected determination coefficient $\mathrm{R}_{a d j}^{2}=0.93$, the coefficient of variation $C V=13.69 \%$, and the predicted determination coefficient $\mathrm{R}_{\text {Pred }}^{2}=0.65$. This indicates that the influencing factors $A, B$ and $C$ have a high degree of correlation with critical across-compression failure force $F_{c}$ of the cotton stalks and that a secondorder response model with a high degree of fitting may be obtained. This model may be used to predict $F_{c}$ of cotton stalks to a high degree of accuracy. According to the regression variance analysis result, the second-order response model of $F_{c}$ of the cotton stalks $v s$. different water contents $(A)$, different sampling locations $(B)$ and different loading speeds $(C)$ is shown in Eq. (3):

$$
\begin{aligned}
& \hat{y}_{2}=142.4-46.3 A+97.39 B+15.85 C-13.94 A B \\
& +2.23 A C+40.79 B C+6.82 A^{2}+57.96 B^{2}-10.29 C^{2} .
\end{aligned}
$$

In the case of directly ignoring the influences of nonsignificant influencing factors on the second-order response model in the above formula, it may be simplified as follows:

$$
\hat{y}_{2}=142.4-46.3 A+97.39 B+40.79 B C+57.96 B^{2} \text {. }
$$

In summary, both water content $A$ and sampling location $B$ have a significant influence on $F_{\max }$ and $F_{c}$ of cotton stalks, and most particularly, the sampling location $B$ of the cotton stalks has the largest influence on $F_{\max }$ and $F_{c}$, while the loading speed $C$ has a small influence on the shearing and across-compression mechanical characteristics of cotton stalks.

In order to better observe the trend of influence of different water contents $A$, different sampling locations $B$, and different loading speeds $C$ on $F_{\max }$ and $F_{c}$ of cotton stalks, 2 factors from the 3 factors mentioned above are fixed at the centre level 0 point to obtain the law of influence of another influencing factor on $F_{\max }$ and $F_{c}$ of cotton stalks (Fig. 4).

As shown in Fig. 4a, when the water content $A$ of the cotton stalks gradually rises to within the range of $10 \sim 30 \%$, $F_{\max }$ of the cotton stalks decreases significantly, while when the water content $A$ of the cotton stalks gradually increases to fit within the range of $30 \sim 50 \%, F_{\max }$ of the cotton stalks also slowly rises. It may be derived from this that: when the water content $A$ of cotton stalks is low, the cotton stalks have a significant degree of rigidity and low flexibility, thereby leading to an increase in $F_{\max }$ of cotton stalks; as the water content $A$ increases, the flexibility of the cotton stalks increases continuously, thus resulting in a trend of increase in $F_{\max }$ of cotton stalks. There is a strong correlation between the shear force and the water content of cotton stalks. Eissa et al. (2008) and Sessiz et al. (2013) have expressed relevant research results. As the water content of the cotton stalks increases from 10 to $30 \%$, the shear force of the cotton stalks decreases gradually, and the shearing mechanical properties of barley and other stalks also show such a dependency (Tavakoli et al., 2009). When the water content of the cotton stalks changes in the range of $30 \sim 50 \%$, the shear force of the cotton stalks changes less, and the closer the water content of the cotton stalks is to $30 \%$, the more the shear force of the cotton stalks is lowered. Li et al. (2011) and Du et al. (2011) also proved evidence for this dependency in the early cotton stalks shear test. They believed that the shear force of cotton stalks is closely related to the water content. When the water content of the cotton stalks was $30 \sim 50 \%$, the shear strength was in the range of $0.6 \sim 1.8 \mathrm{MPa}$, and the shear work was in the range of $1 \sim 4.5 \mathrm{Nm}$, which was the optimal harvest time of cotton stalks.

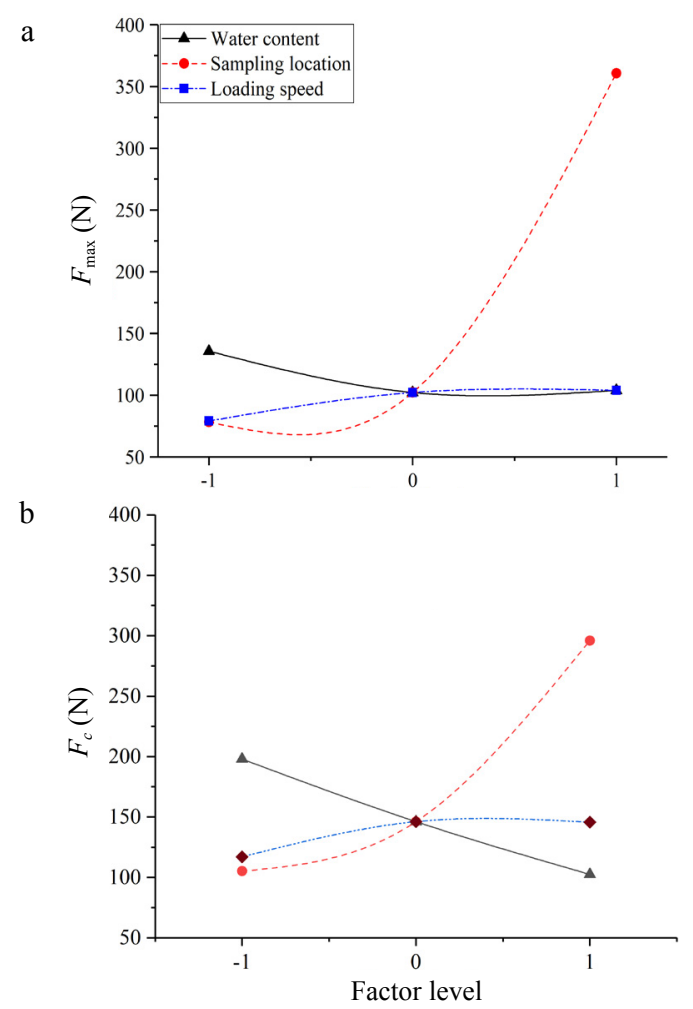

Fig. 4. Trend of influence of single factors on maximum shear force $\left(F_{\max }\right)$ and critical across-compression failure force $\left(F_{c}\right)$ of cotton stalks trend of influence of a single factor on: a $-F_{\max }$ value and $\mathrm{b}-F_{c}$ value. 
As shown in Fig. 4b, there is a large difference between the trend of influence of the water content $A$ on $F_{c}$ of cotton stalks and also on $F_{\max }$ of cotton stalks. With the continuous increase in water content $A, F_{c}$ of cotton stalks shows a very significant decreasing trend, which is due to the reduction in the rigidity of the cotton stalks with the increase in their water content $A$. With the increase in water content, the across-compression failure force decreases, oat stalks also have this dependency. The main reason for this may be that the increase in the water content of the sample forms a higher expansion pressure to resist deformation (Wu et al., 2018). Niklas et al. (1988) also described this dependency. It was assumed that the higher the water content of the stalks with the same internode, the higher the swelling pressure, and the higher the elastic modulus of stalks.

In this case, the relationship models of the water content $A v s . F_{\max }$ and $F_{c}$ of the cotton stalks are as follows:

$$
\left\{\begin{array}{l}
\hat{y}_{1 w}=101.1-15.91 A+19.42 A^{2} \\
\hat{y}_{2 w}=142.4-46.3 A+6.82 A^{2} .
\end{array}\right.
$$

As shown in Fig. $4 a$ and $4 b$, the influence of the sampling location $B$ on $F_{\max }$ and $F_{c}$ of the cotton stalks is extremely significant. When the sampling location $B$ is the upper part of the cotton stalk (level -1), the corresponding $F_{\max }$ and $F_{c}$ of the cotton stalk are at their lowest. When the sampling location $B$ is at the lower part of the cotton stalk (level 1), the corresponding $F_{\max }$ and $F_{c}$ of the cotton stalk are at their highest. There is a large difference between the two cases, and this has a strong correlation with the physical structure characteristics of a cotton stalk. When the sampling location $B$ of a cotton stalk is changed from the bottom to the top, its xylem gradually decreases and its pith core gradually increases, thereby causing the gradual reduction in its rigidity and then a gradual decrease in $F_{\max }$ and $F_{c}$ of the cotton stalk. In this case, the relationship models of the sampling location $B v s . F_{\max }$ and $F_{c}$ of the cotton stalk are as follows:

$$
\left\{\begin{array}{l}
\hat{y}_{1 s}=101.1+137 B+118.1 B^{2} \\
\hat{y}_{2 s}=142.4+97.39 B+57.96 B^{2} .
\end{array}\right.
$$

As shown in Fig. 4, with the increase in loading speed $C$, there is a certain difference between the significance of the increase in $F_{\max }$ and that of the $F_{c}$, but they still have the same increase trend. When the loading speed $C$ is increased from 20 to $30 \mathrm{~mm} \mathrm{~min}^{-1}, F_{\max }$ and $F_{c}$ of the cotton stalk increases significantly; when the loading speed $C$ is further increased from 30 to $40 \mathrm{~mm} \mathrm{~min}^{-1}, F_{\max }$ and $F_{c}$ of the cotton stalk increases slowly. This also indicates that the loading speed $C$ has a minor influence on the shearing and across-compression mechanical characteristics of the cotton stalks, but with the increase in the loading speed $C$, the power consumption also increases. In this case, the relationship models of the loading speed $C v s . F_{\max }$ and $F_{c}$ of the cotton stalks are as follows:

$$
\left\{\begin{array}{l}
\hat{y}_{1 l}=101.1+12.57 C-9.26 C^{2} \\
\hat{y}_{2 l}=142.4+15.85 C-10.29 C^{2} .
\end{array}\right.
$$

A cotton stalk is mainly composed of an outer covering, xylem, and a pith core from the outside to the inside, and the xylem gradually decreases from the bottom to the top, while the pith core gradually increases in size. As the sampling position of the cotton stalk gradually changes from the bottom to the top, the maximum shearing force of the cotton stalk gradually decreases. This dependency is also expressed by Aydın and Arslan (2018) concerning the shearing mechanical properties of the cotton stalk at the top of cotton during the growth period. It is believed that the closer the cotton stalk is to the top of the cotton, the lower the proportion of fibre tissue and xylem in the cotton stalk, which results in the shearing force of cotton stalk decreasing gradually, but the closer to the root of cotton, the greater the shearing force of the cotton stalk. Zhang et al. (2017) and Huang et al. (2016) also explained this rule. Ádám et al. (2019) conducted shearing and across-compression tests on a corn stalk, which also showed that the bottom of the stalk had a stronger resistance to the external load than the middle and top of the stalk. As the sampling area of the corn stalk was moved up from the bottom to the top, the compression and shear work required during the test decreased significantly.

According to the regression variance analysis results in Table 4, the interaction term $A C$ is a significant influencing factor for the maximum shear force $F_{\max }$ of the cotton stalks (Fig. 5), that is, the interaction between the water content $A$ and the loading speed $C$ has a significant influence on the maximum shear force $F_{\max }$ of the cotton stalks (Fig. 6); the interaction term $B C$ is an extremely significant influencing factor on $F_{c}$ of the cotton stalks, that is, the interaction between the sampling location $B$ and the loading speed $C$ has an extremely significant influence on $F_{c}$ of the cotton stalks. Therefore, this part of the analysis ignores other non-significant interaction terms, and only analyses the law of change of the interaction term $A C$ affecting $F_{\max }$ of the cotton stalks and the interaction term $B C$ affecting $F_{c}$ of the cotton stalks.

Figure 5 shows the variation trend in the influence of the interaction between water content $A$ and loading speed $C$ on $F_{\max }$ of cotton stalks. As shown in the figure, with the increase in the water content $A, F_{\max }$ of the cotton stalks tends to change to a small extent; when the level ranges from -1 to 0 , that is, when the water content of the cotton stalks is $10 \sim 30 \%, F_{\max }$ of the cotton stalks tends to decrease gradually as the water content $A$ increases. When the level ranges from 0 to 1 , that is, when the water content of the cotton stalks is $30 \sim 50 \%, F_{\max }$ of the cotton stalks tends to increase 
gradually as the water content $A$ increases. By contrast, when the loading speed $C$ changes within the level range of $-1 \sim 1$, that is, when the loading speed $C$ is $20 \sim 40 \mathrm{~mm} \mathrm{~min}^{-1}$, $F_{\text {max }}$ of the cotton stalks tends to increase gradually as the loading speed $C$ increases. It may be derived from this that the variation law of the influence of water content $A$ with loading speed $C$ on $F_{\max }$ of cotton stalks is consistent with the analysis of single factors.

Figure 6 shows the variation trend of the influence of the interaction between sampling location $B$ and loading speed $C$ on $F_{c}$ of the cotton stalks. As shown in the figure, with the variation in the sampling location $B, F_{c}$ of cotton stalks changes significantly. When the level ranges from -1 to 1 , that is, when the sampling location of the cotton stalk changes from top to bottom, $F_{\max }$ of the cotton stalk tends to increase gradually, which is consistent with the single factor analysis result. When the loading speed $C$ varies within the level range of $-1 \sim 1$, that is, when the loading speed is

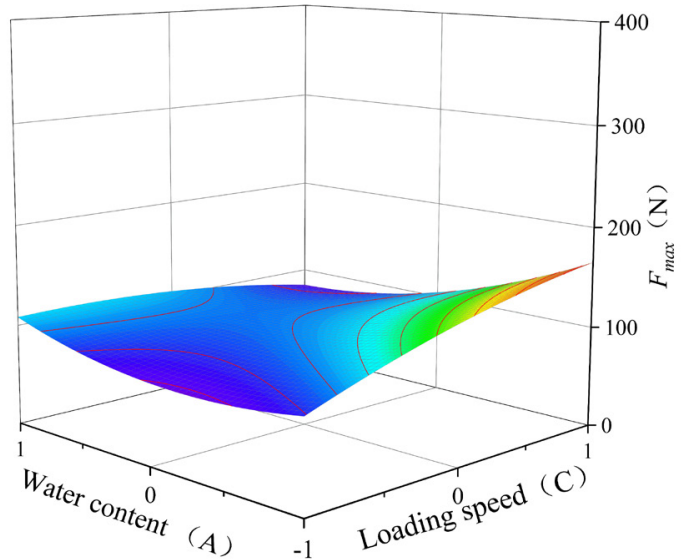

Fig. 5. Trend of influence of the interaction term $A C$ on the $F_{\max }$ value.

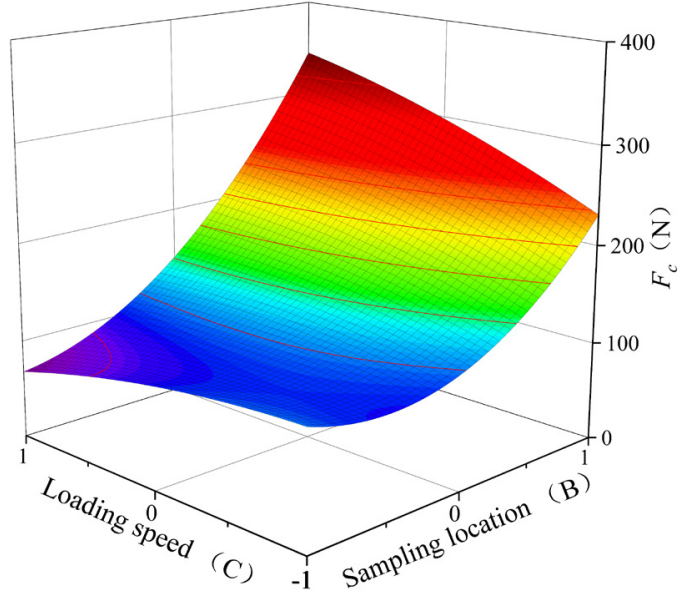

Fig. 6. Trend of influence of the interaction term $B C$ on the $F_{c}$ value.
$20 \sim 40 \mathrm{~mm} \mathrm{~min}^{-1}, F_{c}$ of the cotton stalk tends to decrease gradually as the loading speed $C$ increases, which is different from the single factor analysis result. This phenomenon is most probably caused by the interaction between the sampling location $B$ and the loading speed $C$. In addition, due to the impact of the interaction between the two factors, $F_{c}$ of the cotton stalk still tends to increase significantly as the level of the two factors varies from low to high.

In summary, in order to achieve the effective cutting or crushing of cotton stalks in the process of harvesting and processing the cotton stalks mixed with film residues, the external load applied to the cotton stalks must be greater than $F_{\text {max }}$ and $F_{c}$ of the cotton stalks; moreover, the influence of the $F_{\max }$ and $F_{c}$ on the cotton stalks shall be considered to some extent in the crushing method selection, crushing machine design, crushing mechanism research, and crushing device development in the separation of film residue mixtures after harvesting with machinery in cotton fields. According to an analysis of the second-order response model using response surface methodology, both $F_{\text {max }}$ and $F_{c}$ reach a theoretical maximum and are at 419.1 and $409.0 \mathrm{~N}$ respectively when the level of the water content $A$ is -1 , the level of the sampling location $B$ is 1 and the level of the loading speed $C$ is 1 , that is, when the water content is $10 \%$, the sampling location is in the lower part of the stalk and the loading speed is $40 \mathrm{~mm} \mathrm{~min}^{-1}$. This is consistent with the change trend in the analysis results of the above-mentioned variable factors. If the sampling location of the cotton stalk is in the lower part of the stalk, an optimal theoretical minimum corresponding to the shearing and across-compression mechanical characteristics of the cotton stalk is reached. When the obtained $F_{\max }=335.7 \mathrm{~N}$, and $F_{c}=217.2 \mathrm{~N}$; in this case, the loading speed is $20 \mathrm{~mm} \mathrm{~min}^{-1}$, while the water content in this state is between 30 and $50 \%$. This indicates that this parameter range requires low power consumption during the harvesting and processing of cotton stalks and the crushing of film residue mixtures. It is recommended to carry out the crushing of cotton stalks and film residue mixtures within this parameter range.

\section{CONCLUSIONS}

Shearing and across-compression tests were conducted on cotton stalks using the response surface methodology and a universal testing machine taking water content, sampling location and loading speed as variables, the maximum shear force and critical across-compression failure force of the cotton stalks as dependent variables. The experiments were conducted using as the main research objects the stalks of a major cotton variety grown using dwarf-denseearly techniques in the cotton planting area in the Northern Tianshan Mountains, Xinjiang, which were later returned to the field. The conclusions are as follows: 
1. According to the regression variance analysis of the shearing test results of the cotton stalks using response surface methodology, the sampling location is an extremely significant factor in the maximum shear force of the cotton stalks, water content is a significant factor in the maximum shear force of cotton stalks, and the influence of the interaction between water content and the loading speed on the maximum shear force of cotton stalks is also significant. According to an analysis of the across-compression test results of cotton stalks, the water content and sampling location are extremely significant factors affecting the critical across-compression failure force of cotton stalks, and the interaction term between the sampling location and loading speed is also an extremely significant factor affecting the critical across-compression failure force of cotton stalks.

2. The model coefficient, the determination coefficient, the corrected determination coefficient, the coefficient of variation and the predicted determination coefficient of the second-order response model are constructed by each influencing factor together with the maximum shear force and the critical across-compression failure force of cotton stalks are characterized by high fitting degree, high resolution and high predictability.

3. According to an optimization analysis taking the maximum of the maximum shear force and the critical across-compression failure force as response indexes, the maximum shear force and the critical across-compression failure force are 419.1 and $409.0 \mathrm{~N}$ respectively when the water content is $10 \%$, the sampling location is the lower part of the stalk and the loading speed is $40 \mathrm{~mm} \mathrm{~min}^{-1}$. When the sampling location of a cotton stalk is the lower part, an optimization process may be carried out taking the theoretical minimum of the maximum shear force and the critical across-compression failure force as the target. In this case, the obtained theoretical minimum of the maximum shear force and the critical across-compression failure force is 335.7 and $217.2 \mathrm{~N}$ respectively; also the loading speed is $20 \mathrm{~mm} \mathrm{~min}{ }^{-1}$, while the water content is between 30 and $50 \%$, although it is more commonly closer to $30 \%$.

Conflict of interest: The Authors declare that they have no conflict of interest.

Compliance with ethical requirements: This study does not contain any experiment involving human or animal subjects.

\section{REFERENCES}

Aydın İ. and Arslan S., 2018. Mechanical properties of cotton shoots for topping. Ind. Crops Prod., 112, 396-401. https:// doi.org/10.1016/j.indcrop.2017.12.036
Ádám K. and György K., 2019. Physical characteristics and mechanical behaviour of maize stalks for machine development. Int. Agrophys., 33, 427-436. https://doi.org/10.31545/ intagr/113335

Chen M.J., Wang Z.W., Qu H.L., Chen Y.S., Liu K.K., and Song D.P., 2015. Bending and tensile properties tests of the cotton-stalk. J. Chinese Agric. Mechan., 36(5): 29-32.

Chen X.G. and Zhao Y., 2010. Development of double-film mulch precision planter for cotton seeding. Trans. Chinese Soc. Agric. Eng., 26(4): 106-112.

Ding L.P., Chen Y.C., Ge Y., and Wang L., 2016. Research on the shear mechanical property of cotton stalks. J. Chinese Agric. Mechan., 37(2): 116-118+122.

Dong H.G., Liu T., Li Y.G., Liu H.F., and Wang D., 2013. Effects of plastic film residue on cotton yield and soil physical and chemical properties in Xinjiang. Trans. Chinese Soc. Agric. Machinery, 29(8): 91-99.

Du X.J., Li Y.D., Yan S.T., Li X.Z., Song Z.H., and Li F.D., 2011. Mechanics characteristics of cotton stalks. Trans. Chinese Soc. Agric. Machinery, 42(4): 87-91.

Eissa E., Gomaa A.H., Baiomay M.H., and Ibrahim A.A., 2008. Physical and mechanical characteristics for some agricultural residues. Misr J. Agric. Eng., 25(1), 121-147.

Gao T.H., Yan Y.F., Li F.D., Li Y.D., Tian F.Y., Chen C.K., and Song Z.H., 2016. Shear mechanical properties of cotton stalks at the harvesting time based on response surface methodology. China Sciencepaper, 11(22): 2542-2547.

Hirai Y., Inoue E., Mori K., and Hashiguchi K., 2002. Investigation of mechanical interaction between a combine harvester reel and crop stalks. Biosys. Eng., 83(3), 307-317. https://doi.org/10.1006/bioe.2002.0118

Huang J., Liu W., Zhou F., Peng Y., and Wang N., 2016. Mechanical properties of maize fibre bundles and their contribution to lodging resistance. Biosys. Eng., 151, 298-307. https://doi.org/10.1016/j.biosystemseng.2016.09.016

Jha S.K., Singh A., and Kumar A., 2008. Physical characteristics of compressed cotton stalks. Biosys. Eng., 99(2), 205-210. https://doi.org/10.1016/j.biosystemseng.2007.09.020

Li Y.D., Du X.J., Song Z.H., and Li F.D., 2011. Test of shear mechanical properties of cotton stalks. Trans. Chinese Soc. Agric. Eng., 27(2): 124-128.

Liu J.G., Bian X.M., Li Y.B., and Sun Y.Y., 2008. Effects of long-term continuous cropping of cotton and returning cotton stalk into field on soil biological activities. J. AgroEnviron. Sci., 29(02): 246-250.

Liu L., Chen G.X., and Su F., 2014. Analysis on tensile properties of cotton stalks. J. Southern Agric., 45(11): 2031-2035.

Meng H.B., Han L.J., and Wang J.C., 2005. Development of the test2bed for testing the mechanical properties of straw materials. Trans. Chinese Soc. Agric. Machinery, 21(5): 77-80.

Niklas K.J. and Moon F.C., 1988. Flexural stiffness and modulus of elasticity of flower stalks from allium sativum as measured by multiple resonance frequency spectra. American $\mathrm{J}$. Botany, 75(10), 1517-1525. https://doi.org/10.1002/j.1537-2197.1988.tb11225.x

Qin C.L., Zhou L., Wang L.Y., and Sun J.L., 2017. Experiment on Shear and bending characteristics of Cotton stalk based on Quadratic regression orthogonal rotation combination Design. Jiangsu Agric. Sci., 45(23): 203-206. 
Sessiz A., Eliçin A.K., Esgici R., Özdemir G., and Nozdrovicky L., 2013. Cutting properties of olive sucker. Acta Technol. Agric., 3, 82-86. https://doi.org/10.2478/ata-2013-0021

Shen M., Zhang G.Z., Xia J.F., Zhou Y., and Xu Q.C., 2010a. Research on the mechanical properties of the bottom of cotton stalk at harvest time. J. Shanxi Agric. University, 30(1): 49-51.

Shen X.Y., Wang P., Jiang S., and Xu S.Y., 2010b. Study on mechanical property of compression and shearing of cotton stalks. J. Agric. Mechan. Res., 32(9): 155-158.

Shi N., Guo K.Q., Fan Y.J., Liu B.X., and Yuan X.L., 2017. Peeling and shearing mechanical performance test of cotton stalks in extrusion state. Trans. Chinese Soc. Agric. Eng., 33(18): 51-58.

Tan L.L., Wang C.Y., Li Y.F., and Wang Y.D., 2013. Study on the testing experiment of mechanical property of cotton straws. Xinjiang Agric. Sci., 50(8): 1513-1518.

Tavakoli H., Mohtasebi S.S., Jafari A., and Nazari G.M., 2009. Some engineering properties of barley straw. Appl. Eng. Agric.,25(4),627-633.https://doi.org/10.13031/2013.27453

Wanjura J.D., Barnes E.M., Kelley M.S., Holt G.A., and
Pelletier M.G., 2014. Quantification and characterization of cotton crop biomass residue. Industrial Crops Products, 56, 94-104. https://doi.org/10.1016/j.indcrop.2014.02.019

Wu J., Huang Y., Wang Y.Y., and Wang W.X., 2004. Study on axial compression properties of cotton stalks. J. Agric. Mechan. Res., 4: 148-149+152.

Wu M., Pan H.Y., Zhao D.L., and Li D., 2018. Analysis of physicochemical composition and dynamic mechanical properties of Avena sativa stalk. Trans. Chinese Soc. Agric. Machinery, 49(S1): 447-455.

Zhang J.T., Li H.T., and Wang C.Y., 2014. Static mechanical properties experimental study of cotton stalks. J. Chinese Agric. Mechan., 35(2): 82-84.

Zhang J.X., Wang T.J., Chen M.J., Zhao W.S., Wang Z.W., Liu K.K., Yeerbolati T., Wang Y.C., Liu X., and Liu A.M., 2019. Design of toothed disc cotton stalk harvester. Trans. Chinese Soc. Agric. Eng., 35(15): 1-8.

Zhang K., He Y., Zhang H., and Li H., 2017. Research on mechanical properties of corn stalk. AIP Conf. Proc., 2, 25-26, Wuhan, China. 